\title{
Health sector preaches patient privacy, but what about physician privacy?
}

\author{
[ Cite as: CMAJ 2019 August 26;191:E949-50. doi: 10.1503/cmaj.109-5786
}

Posted on cmajnews.com on August 06, 2019.

hysicians are required by law to protect their patients' health information. But as technology makes it easier for the public to capture information about health care providers, is physician privacy also being protected adequately?

Dr. Andrew Wilner, an associate professor of neurology at the University of Tennessee Health Science Center, argues that physician privacy is often overlooked. Recently, for example, a patient's sister took his photo and shared it on Instagram without his consent.

"I felt that my personal privacy, and the privacy of our medical interaction, had been violated," Wilner wrote in a Medscape commentary.

Patients are pulling smartphones out in emergency departments (EDs), too. A recent study by researchers at the University of Saskatchewan found that more than $80 \%$ of the 156 ED clinicians surveyed had patients who wanted to record video of their procedures. Of the 110 patients who participated in the survey, $62 \%$ thought they should be allowed to record video, compared to just $28 \%$ of clinicians.

Dr. Andrew Donauer, a family medicine resident at the University of Saskatchewan who coauthored the study, said that although most patients ask permission to record, there are some who whip out their smartphones unexpectedly. "You glance to the side and you see somebody's recording you," he said.

The majority of patients surveyed indicated they wanted to record procedures for mementos and to share with friends and family. Dr. James Stempien, head of emergency medicine for the Saskatchewan Health Authority and a coauthor of the study, said doctors want patients to have positive memories of their ED stays, but clinicians have no control over who can see the videos when patients post them online.

"We want to have a good relationship with our patients, but we also want to have some degree of control over our privacy as well," he said. This balance can be especially difficult to strike when patients ask to record in spaces where other patients, families and clinicians might be visible.

Until the health sector develops recording policies to guide clinicians, video or audio recordings should only be permitted in private spaces where "no faces or genitals or confidential personal health information are shown (or heard)," recommended the study's authors. Vid-

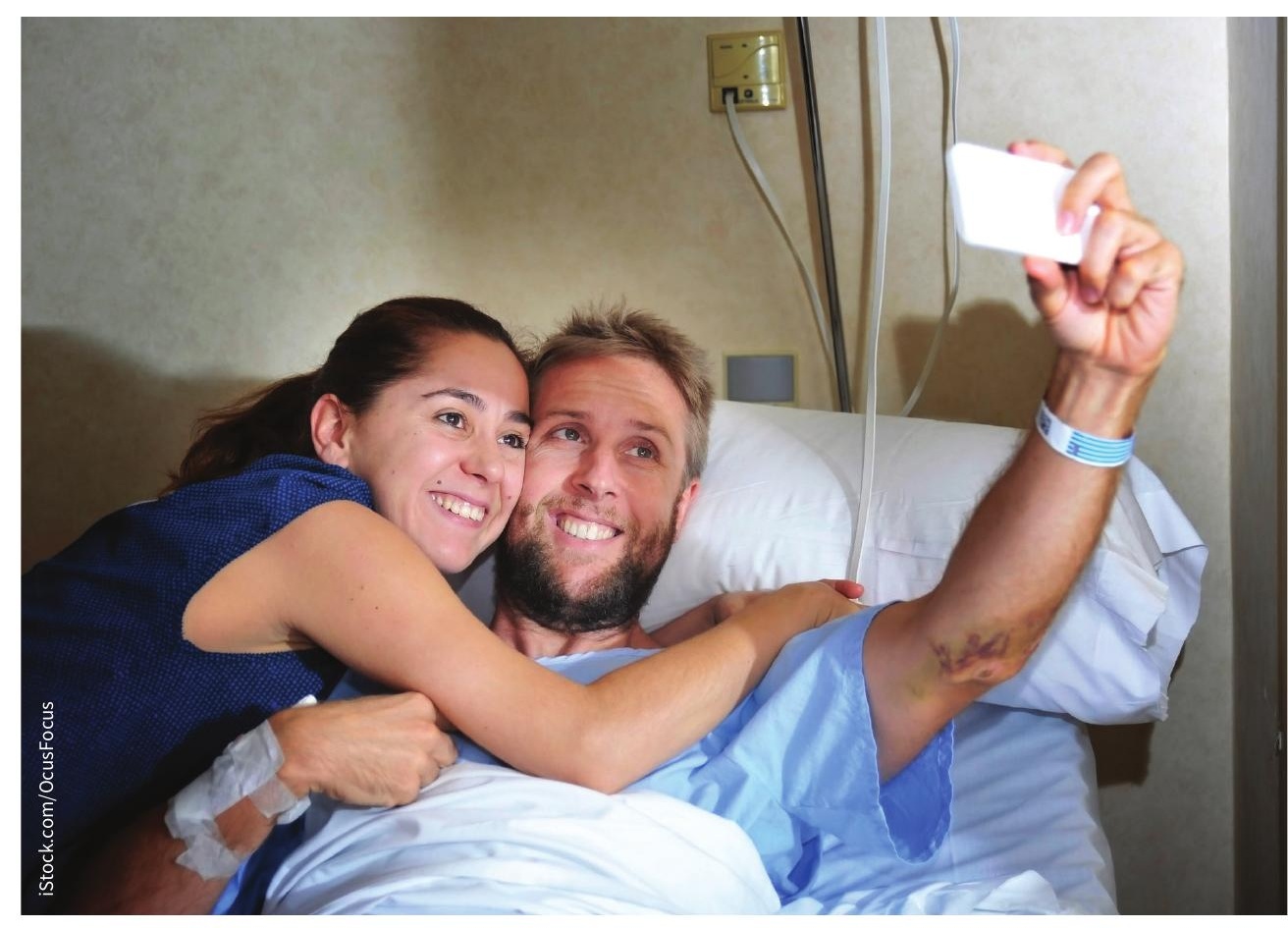

In the smartphone era, it's not uncommon for patients to record video of their treatments in hospitals. eos should focus solely on procedures with consent from all parties present.

The Canadian Medical Protective Association (CMPA) has seen an increased in the number of calls from physicians worried about patients recording appointments in recent years, according to Dr. Daniel Tardif, its director of regional affairs and chief privacy officer. Some patients plan to share photos or videos, but others record clinical visits in hopes of better retaining information. When done respectfully, Tardif said, such recordings can be a "very good capture of what happened during that session."

Toronto-based lawyer Elyse Sunshine recommends that doctors create policies to manage recording in their practices. Without one, Sunshine said, "it's difficult 
after the fact to say to the patient, 'You shouldn't have done that."

Dr. Alykhan Abdulla, a family physician in Manotick, Ontario, has implemented such a policy, and asks patients to limit recordings to the last few minutes of appointments, when he delivers succinct summaries of what was discussed.

Another time when physician privacy may be violated in the United States, according to Wilner, occurs when doctors are required to share personal information in applications for state licences and hospital privileges. While practising as a locum, Wilner went through such pro- cesses routinely and "felt that many of the questions were inappropriate."

He recalls being asked questions about mental and physical health issues, medications, criminal convictions (even if expunged), divorce and childcare payments. Perhaps most egregious, Wilner said, was that applications required him to sign a release of liability should his employer accidently divulge his personal information.

In a 2010 analysis, CMPA reported that colleges and hospitals increasingly require physicians to disclose personal health information like substance abuse, bloodborne infections and mental illness for licence and privilege applications. CMPA advised physicians to disclose confidential information only if colleges or hospitals say why it is needed, how it will advance patient safety, and how it will be protected.

When it comes to disclosure of personal information, Tardif said, regulators must draw the line between protecting the public and upholding physicians' right to privacy. "Doctors need to feel that they're protected."

Caroline Mercer, Toronto, Ont. 